\title{
Discrimination and support from friends and family members experienced by people with mental health problems: Findings from an Australian national survey
}

A J Morgan ${ }^{1,2}$

N J Reavley ${ }^{1}$

A F Jorm ${ }^{1}$

R Beatson ${ }^{1}$

${ }^{1}$ Centre for Mental Health, Melbourne School of Population and Global Health, The University of Melbourne, Australia

${ }^{2}$ School of Psychology and Public Health, La Trobe University, Bundoora, Australia

Corresponding author:

Amy J Morgan, Melbourne School of Population and Global Health, The University of Melbourne, 207 Bouverie Street, Parkville, 3010, Australia.

Email: ajmorgan@unimelb.edu.au, P: +61 39035 7711, ORCID: 0000-0003-3784-0540

Short title: Discrimination and support from friends and family members

Word count: 3199 


\begin{abstract}

\section{Purpose}

To investigate the scope and nature of discrimination and positive treatment experienced by adults with mental health problems from their friends and family in a population-based survey.
\end{abstract}

\title{
Methods
}

An Australian telephone-survey of 5220 adults included 1381 individuals who reported a mental health problem or scored high on a screening questionnaire. Respondents were interviewed about their experience of discrimination and positive treatment from their friends, spouse and other family members. Descriptions of experiences were contentanalysed to identify key characteristics.

\section{Results}

Mental health diagnoses were primarily depression or anxiety disorders, and just over half had received treatment in the last 12 months. Positive treatment from family and friends was far more common than discrimination, reported by $74.1 \%$ of respondents. This was primarily characterised by providing emotional support and maintaining contact, as well as checking on their mental health and being a good listener. Nevertheless, discriminatory behaviours from friends and family were reported by $25.8 \%$ of respondents, with reducing or cutting contact being by far the most common. Friends and family also commonly dismissed that mental illness was real or caused suffering and showed a lack of understanding about mental health problems or treatments and how they can impact behaviour and functioning. 


\section{Conclusions}

This nationally representative study of real life experiences highlights the potential for harm or benefit from a person's social support network. Despite positive experiences being common, there is an ongoing need to reduce mental illness stigma and improve understanding of how to support a loved one with a mental health problem.

\section{Key words}

Mental disorders, stigma, discrimination, social support 


\section{Background}

Stigma and discrimination have a negative impact upon the lives of people with mental disorders. It is a key deterrent of help-seeking [1], interferes with personal relationships and work and educational opportunities [2], and contributes to lower self-esteem and feelings of hopelessness and suicide $[3,4]$. A great deal of research has investigated attitudes towards people with mental health problems, particularly beliefs that they are dangerous and unpredictable, that they are responsible for their problem due to personal weakness, and that they should be avoided [5-7].

More recently, research has turned to understanding the behavioural aspect of stigma discrimination - by directly asking people with mental health problems about unfair treatment they have experienced from others. This is in recognition of the limitations of survey research assessing stigmatising attitudes towards hypothetical situations [8]. People with mental health problems have reported being discriminated against in a range of settings, including within personal relationships, workplaces, health care and housing [9]. Several large-scale surveys of individuals in contact with mental health services, which have used the same measure of discrimination [the Discrimination and Stigma Scale; 10], have found that discrimination is most commonly experienced within personal relationships. Reported rates vary between $40-54 \%$ from family members, $33-50 \%$ from friends, and 21 $39 \%$ in dating or intimate relationships $[11,12,2,9,8]$.

Friends and family members are an important source of mental health support, and unfair treatment from loved ones may be particularly damaging [13]. Qualitative research can aid understanding of what is perceived as unfair or discriminatory treatment from others. There are a growing number of interview studies conducted with people who have mental health 
problems to explore what types of behaviours are perceived as discriminatory, with much of this work focusing on schizophrenia [14]. Several types of behaviours have been identified in this literature [15-19]. The most common is that of social distancing, particularly from friends. This ranges from a reduction in social contact or exclusion from invitations, through to losing relationships altogether. Another consistent finding is friends and family not understanding mental health problems and how they impact behaviour, or making stereotypical judgements such as the person lacks credibility or is "crazy". Overprotective behaviour from family members, involving protection from stressors or a reduction in autonomy, is perceived as unfair or discriminatory despite being well-intentioned. Mistreatment, including verbal and physical abuse, has also been reported from friends and family.

These studies offer insight into the types of behaviour from others that are perceived as discriminatory by adults with mental health problems. However, research thus far has included samples of convenience, participants who were already in touch with treatment services or who were selected for reporting the most discrimination [16]. An epidemiological survey may show different findings, by reducing the likelihood of recruiting participants who have experienced particularly severe discrimination, and including people who have not sought treatment. This may provide more accurate estimations of the most common experiences of discrimination, which could then be used to inform the design of anti-discrimination campaigns.

An important counterpoint to anti-discrimination messages in education campaigns would be to provide information on alternative supportive behaviours in which people might engage. Social networks are well-placed to facilitate early help-seeking for mental health 
problems, and support from friends and family can increase the likelihood of recovery $[20,21]$. Yet, there has been scant research into the types of positive behaviours that friends and family can engage in to best support their loved ones with mental health problems. In one study of individuals with schizophrenia, supportive treatment was perceived as merely being treated with kindness and respect [18]. More detailed accounts of supportive behaviours for people with bipolar disorder have been reported by Doherty and MacGeorge [22], including emotional or conversational support, support managing the illness, and help with activities, housing, finance or transport. Some of these would apply to people with other mental health problems, but some may be more specific to bipolar disorder. However, no population-based studies have systematically assessed experiences of positive treatment related to mental health problems from friends and family members.

In light of the research gaps identified above, this national population-based survey aimed to investigate the scope and nature of discrimination and positive treatment experienced by adults with mental health problems from their friends and family.

\section{Methods}

The data are from a large national survey of Australians about mental health discrimination in a variety of settings [23]. This paper reports on discrimination from friends, family, and spouses experienced by adults with a recent mental health problem. Discrimination experienced in other settings is reported elsewhere (workplace and education settings [24]; health professionals [25]). The survey involved computer-assisted telephone interviews (CATI) with a national sample of 5,220 members of the general community aged 18 years and over. The sample was contacted by random-digit dialling of both landlines and mobile phones (dual frame design). Interviews were conducted between October and December 
2014 by the Social Research Centre survey company. Ethics approval was obtained from the University of Melbourne Human Research Ethics Committee.

\section{Survey interview}

Initial questions covered sociodemographic information, including age, gender, marital status, postcode, country of birth, language spoken at home, level of education and Aboriginal and Torres Strait Islander status. Respondents completed the 12-month version of the Kessler 6 (K6) mental health symptom screening questionnaire [26] and were asked whether they had experienced any sort of mental health problem in the last 12 months. Respondents who answered 'yes' to this question were then asked what they thought the problem was. For the purposes of the study, respondents were considered to have a mental health problem if they either scored in the high range on the $K 6(>=19)$ or specified any of the following mental health problems: depression/major depression, attempted suicide or self-harm, anxiety/anxiety disorder, post-traumatic stress disorder/PTSD, agoraphobia, panic disorder, obsessive-compulsive disorder/OCD, social phobia, generalised anxiety disorder/GAD, eating disorder/anorexia/bulimia, schizophrenia/paranoid schizophrenia, schizoaffective disorder, psychosis/psychotic, bipolar/bipolar disorder/manic-depressive disorder, mental illness, personality disorder/borderline personality disorder, attention deficit-hyperactivity disorder/ADHD, Autism/Asperger's and nervous breakdown.

These respondents were then asked a series of questions about their experiences of discrimination and positive treatment over the past 12 months in a range of domains, including from friends, spouses and family members. Respondents were told "discrimination occurs when people are treated unfairly because they are seen as being different from others". In relation to friends, respondents were first asked, "Have any of your friends 
avoided you because of the emotional or mental health problems you have told me about?". Next they were asked "Have any of your friends discriminated against you in other ways because of these problems?" and "Have any of your friends treated you more positively because of these problems?". If respondents answered 'yes' to either of the latter two questions, they were then asked, "Can you please describe what happened?". The same questions were then asked in relation to family members and spouses. Answers were transcribed verbatim by interviewers.

\section{Content analysis}

Respondent descriptions of discrimination and positive treatment from their spouse, family, and friends were content analysed to identify key characteristics [27]. A coding framework was developed which included instructions with examples and counter-examples for each code. This was developed in an iterative process, whereby an initial coding system was created and refined through discussion and double-coding of a sample of approximately $10 \%$ of responses by three authors (AM, AJ, NR). Sampled responses were selected in order to represent the full range of codes. Coding discrepancies were discussed until consensus was reached for both the coding system and the response in question. Once the coding framework was finalised, one of the authors (AM or RB) coded the remaining discrimination and positive treatment responses. A response could be coded into more than one category. Discussion with a second author was necessary for some responses. Responses that could not be interpreted, did not make sense, or required very strong assumptions about the respondent's meaning were not coded. Only categories with at least $4 \%$ frequency in at least one domain are presented. 


\section{Statistical analysis}

A pre-weight was applied to adjust for the dual frame design and the respondent chance of selection. The achieved sample was close to the Australian national population in terms of geographic distribution, however, there was an under-representation of males and of younger adults, and an over-representation of university-educated individuals and people with an English-speaking background. These biases were adjusted for by 'raking' (also known as rim weighting or iterative proportional fitting) to account for known population proportions of gender, age, education level, region and telephone status. Raking is the preferred approach for overcoming non-response biases in telephone surveys, as it can incorporate a wider range of sociodemographic variables into the weighting formula [28]. Analyses were performed using Intercooled Stata 13 (StataCorp LP, Texas, USA).

\section{Results}

Out of 5220 interviews conducted, $1381(28.8 \%)$ respondents were classified as having a mental health problem and were asked the questions about their experiences of discrimination and positive treatment. Most of these (1159) reported an in-scope mental health problem and the remaining 222 respondents had $\mathrm{K} 6$ scores of 19 or above. The most common mental health problem was depression (55.6\%), followed by anxiety disorders (including PTSD and OCD; 45.2\%), bipolar disorder (4.6\%), psychotic disorder (2.7\%), eating disorder (2.3\%), and personality disorder (1.2\%) (multiple diagnoses were possible). Over half $(57.5 \%)$ of the sample had received treatment for a mental health problem in the last 12 months. The sample age distribution was: $18-29$ years (29.2\%), 30-59 years $(58.0 \%)$ and 60 years or older $(12.8 \%)$. There were more women $(56.4 \%)$ than men $(43.5 \%)$ classified as having a mental health problem. 
A quarter of respondents (25.8\%) reported discrimination from their friends, spouse or other family members, and there were 424 descriptions of how respondents were treated unfairly by them. Twelve categories of discrimination were identified, and the most common experience was friends and family reducing or cutting contact with respondents (see Table 1). This included avoidance, exclusion, distancing, and even losing friendships because of the respondent's mental health problem. See Table 2 for examples of each type of discrimination experience. Respondents also reported friends and family were dismissive that their mental illness was real or caused suffering; lacked understanding about the respondent's illness, including how the illness affects them, its causes, and the impact of treatment on functioning; and judged them because of their behavior (e.g. worthless, stupid, lazy, dangerous). Reports of others expressing anger or frustration or getting into arguments with the respondent were more commonly reported from spouses than friends and other family members, as was being teased or experiencing verbal abuse. Less frequently reported behaviors were being stereotyped as 'crazy' or having their behavior always interpreted through a mental health lens; being treated as incompetent or a bit differently or strangely; telling others about their mental health problem without their permission; being overprotective by removing potential stressors; and being physically abusive.

Experiencing positive treatment was more common than discrimination, as $74.1 \%$ of respondents reported this from their friends, spouse or other family members. There was no association between being discriminated against and being treated more positively by friends and family (Cramer's $V=.06, p=.088$ ). Being treated more positively from friends 
and family was reported by $78.6 \%$ of respondents who reported discrimination, versus 73.1\% of respondents who reported no discrimination.

There were 1745 responses that were coded into 9 categories of positive treatment. Most respondents reported that their friends and family were emotionally supportive in general terms, such as being caring, understanding, nice, or helpful (see Tables 3 and 4). The second most common positive treatment was friends and family maintaining or increasing contact with respondents. Respondents also reported friends and family checking on them to see how they are going and whether they are ok, trying to cheer them up, and talking or listening to the respondent about their issues or sharing their own experiences related to mental health. Some types of positive treatment were more commonly reported from spouses than friends or other family members. These included adjusting expectations of what the respondent can do in acknowledgment of their problem, or providing practical assistance, such as helping with household chores, childcare, housing, financial support, or taking them to appointments. A small proportion of respondents reported friends and family encouraging engagement in positive activities, such as getting out of the house or being more social, or encouraging healthy habits relating to diet, sleep, exercise, or substances. Some responses were infrequently reported and were coded under Other. These, included giving advice, sending gifts, encouraging professional help-seeking, making an effort to avoid negative interactions with the respondent, and an improved relationship with their friend, family member, or spouse.

\section{Discussion}

This study investigated the frequency and types of discriminatory or supportive behaviours people with mental health problems reported experiencing from their loved ones. 
Discriminatory behaviours were reported by $25.8 \%$ of the sample, with social distancing (reducing or cutting contact) being by far the most common. Also common were dismissive treatment and ignorance about mental health problems or treatments and how they can impact behaviour and functioning. There was some variation in frequency of experience across relationship type, as reports of social distance were more common from friends, and spouses tended to engage in more verbal abuse and arguments than friends or family members. This may reflect the closeness or proximity of the relationship, as spouses would be less able to reduce contact than friends. In contrast to the minority who reported discrimination, most respondents (74.1\%) reported some form of positive treatment from family and friends related to their mental health problem, which was primarily emotional support and contact, as well as checking on their mental health and being a good listener. Positive treatment was common even in respondents who reported discrimination, which may be due to different responses from multiple people in a person's social network, or different responses over time from the same individual. This nationally representative study of real life experiences shows that friends and family are sources of both discrimination and support.

Contextualizing these findings in the prior literature, the types of discrimination experiences reported here are generally consistent with those reported in other studies. For instance, social distancing from friends and family was the main form of discrimination reported by adult mental health service users $[15,16]$, and others not understanding their experiences or showing any empathy was also common. The desire to reduce social contact may be to avoid the risks (e.g., violence) associated with people with mental illness [29], but avoidance may also be due to friends and family not being able to cope with the person's mental 
illness, particularly when they are most unwell [16]. Respondents identified overprotection and physical abuse as discriminatory behaviours, but they were less commonly reported in our sample compared to previous research focused on schizophrenia [18].

In contrast, the prevalence estimates of discrimination from friends and family were lower in our study than in other surveys, where up to half of respondents reported discrimination from family or friends [e.g., 12,9]. There may be several reasons for this difference, including the use of a different interview measure (which had a focus on discrimination in the past 12 months only) and sampling of the public rather than mental health service users. Moreover, most respondents reported a depressive or anxiety disorder and few reported psychotic illnesses, which tend to be more highly stigmatised $[6,7]$. Alternatively, Australian national campaigns to reduce stigma may be a factor, as there is evidence that the desire for social distance from those with depression has decreased over time in Australia [30], but has remained unchanged in other countries [31].

Results suggest that the level of stigma and mental health literacy in the community could still be improved. Respondents thought that a lack of knowledge or understanding about mental health problems from their friends and family led to them being treated unfairly. Although mental health literacy has improved in Australia in recent years [32], a minority still believe that mental health problems are not real or are due to personal weakness, and would be unwilling to interact socially with a person affected [30]. Programs such as Mental Health First Aid (MHFA), which educates community members on mental health problems and how to assist a loved one to seek help, have been shown to improve mental health knowledge, reduce stigma, and increase helping behaviours [33]. Alongside community education initiatives, there is a role for health professionals to educate carers about their 
loved one's mental illness and how to provide ongoing support. Consumers and carers agree on the importance of active carer participation in mental health care, with carers desiring not only information about mental illness but also how to cope as a carer and provide practical day-to-day support [34,35]. This information and support can range from basic psychoeducation to more intensive skills-based family interventions, which have shown benefits in preventing relapse and reducing hospitalisation [36]. These community and family education initiatives recognise the pivotal role that a person's social networks play in supporting them towards obtaining treatment and achieving recovery.

The study's main limitations were its relatively low response rate, which may affect the generalizability of the results, and the use of an unvalidated measure of discrimination experiences. Although raked weighting was used to improve the representativeness of prevalence estimates, this method can only compensate for sociodemographic biases and not for biases in other variables like discriminatory or supportive experiences. Another limitation is that in a general community sample, more severe mental disorders have a low prevalence, so that the results may not adequately represent the experiences of people with these disorders. The study design also meant that follow-up questions to clarify responses were not possible, and information about the context of each experience was not obtained. This would be possible in a smaller, 'richer' qualitative study that used longer or more detailed interviews, but was not feasible with the large sample size obtained. Furthermore, whilst the study identified a range of behaviours from friends and family perceived as supportive, it did not investigate which types of positive treatment are thought to be most useful to people with a mental health problem. The study's main strength was its use of interviews to ascertain the experiences of people with a wide range of mental health 
problems, rather than assessing stigmatising attitudes towards hypothetical vignettes. The large, population-based sample may also have reduced the likelihood of recruiting respondents who wanted to participate due to experiencing particularly severe discrimination. Furthermore, as the sample included a mix of service-users and non-users, results are less likely to be biased towards underreporting of discrimination from people who have experienced very high levels discrimination avoiding treatment services.

In conclusion, this study found that friends and family engaged in a variety of behaviours that were perceived to be discriminatory by people with mental health problems, particularly social rejection and the enactment of negative or judgemental attitudes. Correspondingly, providing emotional support and maintaining contact were the main positive behaviours reported by respondents from their loved ones. These findings highlight the potential for harm or benefit from a person's social support network, and the ongoing need for efforts to reduce mental illness stigma and improve understanding of how to support a loved one with a mental health problem.

\section{Financial support}

The study was supported by the National Health and Medical Research Council.

\section{Conflict of interest}

The authors declare that they have no conflict of interest. 


\section{Ethical standards}

The authors assert that all procedures contributing to this work comply with the ethical standards of the relevant national and institutional committees on human experimentation and with the Helsinki Declaration of 1975, as revised in 2008.

\section{References}

1. Clement S, Schauman O, Graham T, Maggioni F, Evans-Lacko S, Bezborodovs N, Morgan C, Rüsch N, Brown JSL, Thornicroft G (2015) What is the impact of mental health-related stigma on help-seeking? A systematic review of quantitative and qualitative studies. Psychological Medicine 45 (01):11-27. doi:10.1017/S0033291714000129

2. Lasalvia A, Zoppei S, Van Bortel T, Bonetto C, Cristofalo D, Wahlbeck K, Bacle SV, Van Audenhove C, van Weeghel J, Reneses B (2013) Global pattern of experienced and anticipated discrimination reported by people with major depressive disorder: a crosssectional survey. Lancet 381 (9860):55-62

3. Farrelly S, Jeffery D, Rüsch N, Williams P, Thornicroft G, Clement S (2015) The link between mental health-related discrimination and suicidality: service user perspectives. Psychological Medicine 45 (10):2013-2022. doi:10.1017/\$0033291714003158 4. Livingston JD, Boyd JE (2010) Correlates and consequences of internalized stigma for people living with mental illness: A systematic review and meta-analysis. Soc Sci Med 71 (12):2150-2161. doi:10.1016/j.socscimed.2010.09.030

5. Corrigan PW, Watson AC (2002) Understanding the impact of stigma on people with mental illness. World Psychiatry 1 (1):16-20 
6. Jorm AF, Oh E (2009) Desire for social distance from people with mental disorders. Australian and New Zealand Journal of Psychiatry 43 (3):183-200.

doi:10.1080/00048670802653349

7. Jorm AF, Reavley NJ, Ross AM (2012) Belief in the dangerousness of people with mental disorders: A review. Australian and New Zealand Journal of Psychiatry 46 (11):1029-1045. doi:10.1177/0004867412442406

8. Thornicroft G, Brohan E, Rose D, Sartorius N, Leese M (2009) Global pattern of experienced and anticipated discrimination against people with schizophrenia: a crosssectional survey. Lancet 373 (9661):408-415

9. Thornicroft C, Wyllie A, Thornicroft G, Mehta N (2014) Impact of the "Like Minds, Like Mine" anti-stigma and discrimination campaign in New Zealand on anticipated and experienced discrimination. Australian and New Zealand Journal of Psychiatry 48 (4):360370. doi:10.1177/0004867413512687

10. Brohan E, Slade M, Clement S, Thornicroft G (2013) Development and psychometric validation of the discrimination and stigma scale (DISC). Psychiatry Research 208. doi:10.1016/j.psychres.2013.03.007

11. Corker E, Hamilton S, Henderson C, Weeks C, Pinfold V, Rose D, Williams P, Flach C, Gill V, Lewis-Holmes E, Thornicroft G (2013) Experiences of discrimination among people using mental health services in England 2008-2011. British Journal of Psychiatry 202 (s55):s58-s63. doi:10.1192/bjp.bp.112.112912

12. Hansson L, Stjernswärd S, Svensson B (2014) Perceived and anticipated discrimination in people with mental illness-An interview study. Nordic Journal of Psychiatry 68 (2):100-106. doi:10.3109/08039488.2013.775339 
13. Griffiths KM, Crisp DA, Barney L, Reid R (2011) Seeking help for depression from family and friends: A qualitative analysis of perceived advantages and disadvantages. BMC Psychiatry 11:196-196. doi:10.1186/1471-244X-11-196

14. Mestdagh A, Hansen B (2014) Stigma in patients with schizophrenia receiving community mental health care: a review of qualitative studies. Social Psychiatry and Psychiatric Epidemiology 49 (1):79-87. doi:10.1007/s00127-013-0729-4

15. Hamilton S, Lewis-Holmes E, Pinfold V, Henderson C, Rose D, Thornicroft G (2014) Discrimination against people with a mental health diagnosis: qualitative analysis of reported experiences. Journal of Mental Health 23 (2):88-93.

doi:doi:10.3109/09638237.2014.880408

16. Hamilton S, Pinfold V, Cotney J, Couperthwaite L, Matthews J, Barret K, Warren S, Corker E, Rose D, Thornicroft G, Henderson C (2016) Qualitative analysis of mental health service users' reported experiences of discrimination. Acta Psychiatrica Scandinavica 134:14-22. doi:10.1111/acps.12611

17. Lakeman R, McGowan P, MacGabhann L, Parkinson M, Redmond M, Sibitz I, Stevenson C, Walsh J (2012) A qualitative study exploring experiences of discrimination associated with mental-health problems in Ireland. Epidemiology and Psychiatric Sciences 21 (3):271-279. doi:10.1017/S2045796012000017

18. Rose D, Rose R, Willis E, Brohan N, Sartorius C, Villares K, Wahlbeck G, Thornicroft (2011) Reported stigma and discrimination by people with a diagnosis of schizophrenia. Epidemiology and Psychiatric Sciences 20 (02):193-204 19. Schulze B, Angermeyer MC (2003) Subjective experiences of stigma. A focus group study of schizophrenic patients, their relatives and mental health professionals. Soc Sci Med 56 (2):299-312. doi:10.1016/S0277-9536(02)00028-X 
20. Dour HJ, Wiley JF, Roy-Byrne P, Stein MB, Sullivan G, Sherbourne CD, Bystritsky A, Rose RD, Craske MG (2014) Perceived social support mediates anxiety and depressive symptom changes following primary care intervention. Depression and Anxiety 31 (5):436-442. doi:10.1002/da.22216

21. Nasser EH, Overholser JC (2005) Recovery from major depression: the role of support from family, friends, and spiritual beliefs. Acta Psychiatrica Scandinavica 111 (2):125-132. doi:10.1111/j.1600-0447.2004.00423.x

22. Doherty EF, MacGeorge EL (2012) Perceptions of supportive behavior by young adults with bipolar disorder. Qualitative Health Research 23 (3):361-374.

doi:10.1177/1049732312468508

23. Reavley NJ, Jorm AF (2015) Experiences of discrimination and positive treatment in people with mental health problems: Findings from an Australian national survey. Australian and New Zealand Journal of Psychiatry 49 (10):906-913. doi:10.1177/0004867415602068 24. Reavley NJ, Jorm AF, Morgan AJ (In press) Discrimination and positive treatment towards people with mental health problems in workplace and education settings: Findings from an Australian national survey. Stigma and Health Accepted 2 August 2016

25. Morgan AJ, Reavley NJ, Jorm AF, Beatson R (2016) Experiences of discrimination and positive treatment from health professionals: A national survey of adults with mental health problems. Australian and New Zealand Journal of Psychiatry 50 (8):754-762.

doi:10.1177/0004867416655605

26. Kessler RC, Green JG, Gruber MJ, Sampson NA, Bromet E, Cuitan M, Furukawa TA, Gureje O, Hinkov H, Hu CY, Lara C, Lee S, Mneimneh Z, Myer L, Oakley-Browne M, Posada-Villa J, Sagar R, Viana MC, Zaslavsky AM (2010) Screening for serious mental illness in the general 
population with the $\mathrm{K} 6$ screening scale: results from the WHO World Mental Health (WMH) survey initiative. Int J Methods Psychiatr Res 19 Suppl 1:4-22. doi:10.1002/mpr.310 27. Crowe M, Inder M, Porter R (2015) Conducting qualitative research in mental health: Thematic and content analyses. Australian and New Zealand Journal of Psychiatry 49 (7):616-623. doi:10.1177/0004867415582053

28. Dal Grande E, Chittleborough CR, Campostrini S, Tucker G, Taylor AW (2015) Health estimates using survey raked-weighting techniques in an Australian population health surveillance system. American Journal of Epidemiology 182 (6):544-556.

doi:10.1093/aje/kwv080

29. Corrigan PW (2016) Lessons learned from unintended consequences about erasing the stigma of mental illness. World Psychiatry 15 (1):67-73. doi:10.1002/wps.20295 30. Reavley NJ, Jorm AF (2012) Stigmatising attitudes towards people with mental disorders: Changes in Australia over 8 years. Psychiatry Research 197 (3):302-306. doi:10.1016/j.psychres.2012.01.011

31. Schomerus G, Schwahn C, Holzinger A, Corrigan PW, Grabe HJ, Carta MG, Angermeyer MC (2012) Evolution of public attitudes about mental illness: a systematic review and metaanalysis. Acta Psychiatrica Scandinavica 125 (6):440-452. doi:10.1111/j.16000447.2012.01826.x

32. Reavley NJ, Jorm AF (2012) Public recognition of mental disorders and beliefs about treatment: changes in Australia over 16 years. British Journal of Psychiatry 200 (5):419-425. doi:10.1192/bjp.bp.111.104208

33. Hadlaczky G, Hökby S, Mkrtchian A, Carli V, Wasserman D (2014) Mental Health First Aid is an effective public health intervention for improving knowledge, attitudes, and behaviour: 
A meta-analysis. International Review of Psychiatry 26 (4):467-475.

doi:10.3109/09540261.2014.924910

34. Askey R, Holmshaw J, Gamble C, Gray R (2009) What do carers of people with psychosis need from mental health services? Exploring the views of carers, service users and professionals. Journal of Family Therapy 31 (3):310-331. doi:10.1111/j.1467$6427.2009 .00470 . x$

35. Berk L, Jorm AF, Kelly CM, Dodd S, Berk M (2011) Development of guidelines for caregivers of people with bipolar disorder: a Delphi expert consensus study. Bipolar Disorders 13 (5-6):556-570. doi:10.1111/j.1399-5618.2011.00942.x

36. Corrigan PW, Druss BG, Perlick DA (2014) The impact of mental illness stigma on seeking and participating in mental health care. Psychological Science in the Public Interest 15 (2):37-70. doi:10.1177/1529100614531398 


\section{Tables}

Table 1. Frequency of type of discrimination experienced by respondents from their spouse, family members, and friends

\begin{tabular}{lrrrrrr}
\hline & \multicolumn{2}{c}{ spouse } & \multicolumn{2}{c}{ family } & \multicolumn{2}{c}{ friends } \\
Type of discrimination & $\mathbf{n}$ & \multicolumn{1}{c}{$\%$} & \multicolumn{1}{c}{$\mathbf{n}$} & \multicolumn{1}{c}{$\%$} & \multicolumn{1}{c}{$\mathbf{n}$} & $\%$ \\
\hline Reduced / cut contact & 24 & 34.3 & 63 & 43.2 & 88 & 54.7 \\
Dismissive & 6 & 8.6 & 30 & 20.5 & 23 & 14.3 \\
Lacked understanding & 13 & 18.6 & 30 & 20.5 & 21 & 13.0 \\
Being judged & 10 & 14.3 & 17 & 11.6 & 22 & 13.7 \\
Teasing / verbal abuse & 10 & 14.3 & 9 & 6.2 & 13 & 8.1 \\
Stereotyped & 3 & 4.3 & 4 & 2.7 & 7 & 4.3 \\
Treated as incompetent & 5 & 7.1 & 6 & 4.1 & 0 & 0.0 \\
Treated a bit differently / strangely & 0 & 0.0 & 5 & 3.4 & 8 & 5.0 \\
Told others & 0 & 0.0 & 4 & 2.7 & 7 & 4.3 \\
Expressed anger / frustration / & & & & & & \\
arguments & 14 & 20.0 & 11 & 7.5 & 3 & 1.9 \\
Overprotection & 3 & 4.3 & 3 & 2.1 & 3 & 1.9 \\
Physical abuse & 3 & 4.3 & 3 & 2.1 & 1 & 0.6 \\
Could not be coded & 21 & 23.1 & 20 & 12.0 & 6 & 3.6 \\
\hline
\end{tabular}


Table 2. Example responses for each type of discrimination reported by respondents from their spouse, family members, and friends

\begin{tabular}{|c|c|c|c|}
\hline Type of discrimination & Examples & Domain & Disorder \\
\hline \multirow[t]{3}{*}{ Reduced / cut contact } & A couple of my friends stopped talking to me. [Male, 35-39] & friends & Schizophrenia \\
\hline & $\begin{array}{l}\text { In terms of not making the regular contact, discrimination as to social events as } \\
\text { well. Non-invitations. [Female, 35-39] }\end{array}$ & family & Depression, anxiety disorder \\
\hline & $\begin{array}{l}\text { Doesn't want to be physical, doesn't want to have a physical relationship while } \\
\text { I'm going through this / withdrawing communication wise, not knowing what to } \\
\text { say to me [Female, 35-39] }\end{array}$ & spouse & Panic disorder, GAD \\
\hline \multirow[t]{3}{*}{ Dismissive } & $\begin{array}{l}\text { Basically they don't believe mental illness. They just tell me I'm basically failing } \\
\text { at life, or I'm just too negative [Female, 20-24] }\end{array}$ & family & Depression, anxiety disorder \\
\hline & They just tell you it's all in your head [Female, 25-29] & friends & Depression, anxiety disorder \\
\hline & $\begin{array}{l}\text { They say pull yourself together, or there's other people worse off which you } \\
\text { don't need to hear when you're feeling bad. [Female, 60-64] }\end{array}$ & family & No disorder \\
\hline \multirow[t]{2}{*}{ Lacked understanding } & $\begin{array}{l}\text { Only because of the non-understanding of the illness sometimes makes it hard } \\
\text { and we're going through something at the moment where I'm on heavy } \\
\text { medications and I'm very drowsy and I've been housebound for a long time, } \\
\text { and my family have been saying get out and do things and I just haven't got the } \\
\text { energy, so trying to explain to them is hard enough [Male, 45-49] }\end{array}$ & family & Schizoaffective disorder \\
\hline & $\begin{array}{l}\text { They just reckoned I shouldn't be taking antidepressants because it's no good } \\
\text { for me. [Female, 45-49] } \\
\text { Doesn't understand the disorder the illness responds with anger thinking is } \\
\text { more of a situation where you're just being difficult not a disorder [Female, 60- } \\
64 \text { ] }\end{array}$ & friends & Anxiety disorder, PTSD \\
\hline \multirow[t]{2}{*}{ Being judged } & $\begin{array}{l}\text { Being judgmental. Looked down upon for being weak. [Female, 35-39] } \\
\text { My father said that I was a disappointment to him and my mother. [Male, 55- } \\
\text { 59] }\end{array}$ & $\begin{array}{l}\text { friends } \\
\text { family }\end{array}$ & $\begin{array}{l}\text { Depression, anxiety disorder } \\
\text { Depression, anxiety disorder, } \\
\text { PTSD }\end{array}$ \\
\hline & $\begin{array}{l}\text { Put a lot of blame on me for things I couldn't help at the time. Calling me lazy } \\
\text { because I had no energy [Male, 30-34] }\end{array}$ & spouse & Stress \\
\hline
\end{tabular}




\begin{tabular}{|c|c|c|c|}
\hline \multirow[t]{2}{*}{ Teasing / verbal abuse } & $\begin{array}{l}\text { They've belittled me and put me down [Female, } 45-49] \\
\text { Sometimes he in the past he would tease me for having a mental problem, I } \\
\text { don't like having it but sometimes my spouse would tease me about it, he } \\
\text { doesn't do it now, it's just the stigma attached to it and that teasing can hurt } \\
\text { me [Female, 45-49] }\end{array}$ & family & Schizoaffective disorder \\
\hline & $\begin{array}{l}\text { Being taunted all the time about it. They would make smart-arse jokes and * } \\
\text { like that [Male, 35-39] }\end{array}$ & friends & Nervous breakdown \\
\hline \multirow[t]{2}{*}{ Stereotyped } & $\begin{array}{l}\text { My friends didn't want to visit me because they were scared of crazy people } \\
\text { [Female, 30-34] }\end{array}$ & friends & Depression, psychosis \\
\hline & $\begin{array}{l}\text { Their perceptions of you are then very different, and how they interpret your } \\
\text { behaviour. Everything would be seen with a mental health lens on it. [Female, } \\
\text { 30-34] }\end{array}$ & spouse & No disorder \\
\hline $\begin{array}{l}\text { Treated as } \\
\text { incompetent }\end{array}$ & $\begin{array}{l}\text { Took all responsibility away from me [Female, 30-34] } \\
\text { Can't trust me to make decisions [Male, 55-59] }\end{array}$ & $\begin{array}{l}\text { family } \\
\text { spouse }\end{array}$ & $\begin{array}{l}\text { Bipolar disorder } \\
\text { Depression, anxiety disorder, } \\
\text { PTSD }\end{array}$ \\
\hline $\begin{array}{l}\text { Treated a bit } \\
\text { differently / strangely }\end{array}$ & $\begin{array}{l}\text { Some people are unsure of how to act around me [Male, 50-54] } \\
\text { They would treat you differently or withhold information [Female, 30-34] }\end{array}$ & $\begin{array}{l}\text { friends } \\
\text { family }\end{array}$ & $\begin{array}{l}\text { Depression, anxiety disorder, } \\
\text { schizophrenia } \\
\text { No disorder }\end{array}$ \\
\hline \multirow[t]{2}{*}{ Told others } & They just told others, and stuff [Female, 18-19] & friends & Depression, anxiety disorder \\
\hline & $\begin{array}{l}\text { Probably just a breakdown in family ties, mostly with my mother. When I tried } \\
\text { to discuss it with her she hung up on me and then phoned other siblings and } \\
\text { talked about me. [Female, 35-39] }\end{array}$ & family & PTSD, GAD \\
\hline \multirow[t]{2}{*}{$\begin{array}{l}\text { Expressed anger / } \\
\text { frustration / } \\
\text { arguments }\end{array}$} & $\begin{array}{l}\text { General attitude, general way of being treated, apart from avoidance: anger, } \\
\text { frustration, all those negative words [Female, } 60-64]\end{array}$ & family & Depression \\
\hline & $\begin{array}{l}\text { When he gets frustrated he'll make comments and make me sound like a raving } \\
\text { lunatic. It's more when he's frustrated and angry that he'll focus on my } \\
\text { problems rather than a solution to what we're dealing with [Female, 35-39] }\end{array}$ & spouse & Anxiety disorder \\
\hline Overprotection & $\begin{array}{l}\text { if something could have a potential for me to be a stressor for me I won't be } \\
\text { invited out or they change what's going on [Female, 18-19] }\end{array}$ & friends & $\begin{array}{l}\text { PTSD, borderline personality } \\
\text { disorder }\end{array}$ \\
\hline
\end{tabular}


Thinking that I couldn't do my normal job and wanting me to do less stressful jobs [Female, 35-39]

I was assaulted by my brother for no particular, because he thought I was

vulnerable and took it out on me.[Female, 50-54] family Depression

I was attacked [Female, 50-54] $\quad$ spouse No disorder

Table 3 Frequency of type of positive treatment experienced by respondents from their spouse, family members, and friends

\begin{tabular}{lcrrrrr}
\hline & \multicolumn{2}{c}{ spouse } & \multicolumn{2}{c}{ family } & \multicolumn{2}{c}{ friends } \\
Type of positive treatment & $\mathbf{n}$ & $\mathbf{\%}$ & $\mathbf{n}$ & $\mathbf{\%}$ & $\mathbf{n}$ & \% \\
\hline $\begin{array}{l}\text { Non-specific emotional } \\
\text { support }\end{array}$ & 372 & 81.2 & 392 & 68.2 & 477 & 72.3 \\
Maintained or increased & & & & & & \\
contact & 64 & 14.0 & 195 & 33.9 & 205 & 31.1 \\
Checked on them & 26 & 5.7 & 84 & 14.6 & 101 & 15.3 \\
Talked or listened & 47 & 10.3 & 38 & 6.6 & 84 & 12.7 \\
Tried to cheer up & 40 & 8.7 & 32 & 5.6 & 55 & 8.3 \\
Adjusted expectations & 40 & 8.7 & 25 & 4.3 & 22 & 3.3 \\
Practical assistance & 57 & 12.4 & 42 & 7.3 & 28 & 4.2 \\
Encouraged positive or & & & & & & \\
healthy activities & 20 & 4.4 & 11 & 1.9 & 36 & 5.5 \\
Other & 49 & 10.7 & 65 & 11.3 & 44 & 6.7 \\
Could not be coded & 12 & 2.6 & 13 & 2.2 & 27 & 3.9 \\
\hline
\end{tabular}


Table 4. Example responses for each type of positive treatment experienced by respondents from their spouse, family members, and friends

\begin{tabular}{|c|c|c|c|}
\hline Type of positive treatment & Examples & Domain & Disorder \\
\hline $\begin{array}{l}\text { Non-specific emotional } \\
\text { support }\end{array}$ & $\begin{array}{l}\text { They are supportive and understanding [Male, } 65-69 \text { ] } \\
\text { When they see you're going through a rough time they rally } \\
\text { around you and support you with word or offering to help or just } \\
\text { by being there. [Female, 35-39] } \\
\text { Just being a bit more thoughtful [Female, } 65-69 \text { ] }\end{array}$ & $\begin{array}{l}\text { friends } \\
\text { spouse }\end{array}$ & $\begin{array}{l}\text { Anxiety disorder } \\
\text { Depression }\end{array}$ \\
\hline $\begin{array}{l}\text { Maintained or increased } \\
\text { contact }\end{array}$ & $\begin{array}{l}\text { Trying to stop over as often as they can [Female, 20-24] } \\
\text { Just spent more time with me I guess [Male, 65-69] } \\
\text { Try to catch up more [Male, 25-29] }\end{array}$ & $\begin{array}{l}\text { family } \\
\text { spouse } \\
\text { friends }\end{array}$ & $\begin{array}{l}\text { Depression, anxiety } \\
\text { disorder } \\
\text { Stress } \\
\text { Anxiety disorder }\end{array}$ \\
\hline Checked on them & $\begin{array}{l}\text { Phone calls to check on me [Female, } 45-49] \\
\text { Just a lot more monitoring [Female, 25-29] } \\
\text { Constantly making sure I'm ok [Female, 20-24] }\end{array}$ & $\begin{array}{l}\text { friends } \\
\text { family } \\
\text { spouse }\end{array}$ & $\begin{array}{l}\text { Depression, anxiety } \\
\text { disorder } \\
\text { Depression } \\
\text { Depression, anxiety } \\
\text { disorder }\end{array}$ \\
\hline Talked or listened & $\begin{array}{l}\text { Given me the opportunity to talk about how l'm feeling [Female, } \\
65-69 \text { ] } \\
\text { They also share their stories of mental health problems [Female, } \\
45-49 \text { ] } \\
\text { He listens and lets me vent [Female, } 45-49 \text { ] }\end{array}$ & $\begin{array}{l}\text { family } \\
\text { friends } \\
\text { spouse }\end{array}$ & $\begin{array}{l}\text { Anxiety disorder } \\
\text { Depression, anxiety } \\
\text { disorder } \\
\text { Depression, anxiety } \\
\text { disorder }\end{array}$ \\
\hline Tried to cheer up & $\begin{array}{l}\text { They try to cheer me up [Male, } 40-44] \\
\text { They try to make me happy, take me out and cheer me up [Male, } \\
\text { 20-24] } \\
\text { Always making me look at the brighter side of things and the } \\
\text { future [Female, 55-59] }\end{array}$ & $\begin{array}{l}\text { friends } \\
\text { spouse } \\
\text { family }\end{array}$ & $\begin{array}{l}\text { Depression, } \\
\text { schizophrenia } \\
\text { Depression, anxiety } \\
\text { disorder } \\
\text { Depression, anxiety } \\
\text { disorder }\end{array}$ \\
\hline
\end{tabular}




\begin{tabular}{|c|c|c|c|}
\hline Adjusted expectations & $\begin{array}{l}\text { They understand that some days I can do things and some days I } \\
\text { can't [Male, } 65-69 \text { ] } \\
\text { Degree of forgiveness of not being as productive as I normally am } \\
\text { [Male, } 45-49 \text { ] } \\
\text { My daughter is } 13 \text { years old but she is not disappointed when I } \\
\text { cannot do things with her she doesn't make me feel bad about } \\
\text { letting her down [Female, } 45-49 \text { ] }\end{array}$ & friends & $\begin{array}{l}\text { No disorder } \\
\text { Depression, anxiety } \\
\text { disorder }\end{array}$ \\
\hline \multirow[t]{2}{*}{ Practical assistance } & $\begin{array}{l}\text { Helping, offer to do housework or vacuuming [Female, 50-54] } \\
\text { They've helped me out by taking me to appointments [Female, 50- } \\
54]\end{array}$ & $\begin{array}{l}\text { friends } \\
\text { family }\end{array}$ & $\begin{array}{l}\text { No disorder } \\
\text { Depression }\end{array}$ \\
\hline & $\begin{array}{l}\text { He's happy to take the kids to school in the morning and to pay for } \\
\text { afterschool care [Female, 35-39] }\end{array}$ & spouse & $\begin{array}{l}\text { Borderline personality } \\
\text { disorder }\end{array}$ \\
\hline $\begin{array}{l}\text { Encouraged positive or } \\
\text { healthy activities }\end{array}$ & $\begin{array}{l}\text { Just making sure that I am getting out of the house even if I don't } \\
\text { want to but you have to get out and do things [Female, 40-44] } \\
\text { Encourages healthy habits, good sleeping practices. [Female, 45- } \\
\text { 49] }\end{array}$ & $\begin{array}{l}\text { family } \\
\text { spouse }\end{array}$ & $\begin{array}{l}\text { Depression, attempted } \\
\text { suicide or self-harm } \\
\text { Depression }\end{array}$ \\
\hline
\end{tabular}

